\title{
Characteristics of InGaN-Based Light-Emitting Diodes on Patterned Sapphire Substrates with Various Pattern Heights
}

\author{
Sheng-Fu Yu, ${ }^{1}$ Sheng-Po Chang, ${ }^{1}$ Shoou-Jinn Chang, ${ }^{1}$ Ray-Ming Lin, ${ }^{2}$ \\ Hsin-Hung $\mathrm{Wu}^{2}$ and Wen-Ching $\mathrm{Hsu}^{3}$ \\ ${ }^{1}$ Department of Electrical Engineering, Institute of Microelectronics, Advanced Optoelectronic Technology Center, \\ Center for Micro/Nano Science and Technology, National Cheng Kung University, Tainan 70101, Taiwan \\ ${ }^{2}$ Department of Electronic Engineering, Green Technology Research Center, Chang-Gung University, Taoyuan 333, Taiwan \\ ${ }^{3}$ Sino-American Silicon Products Incorporated, Hsinchu 300, Taiwan
}

Correspondence should be addressed to Sheng-Po Chang, changsp@mail.ncku.edu.tw

Received 5 March 2012; Revised 26 May 2012; Accepted 8 June 2012

Academic Editor: Sheng-Rui Jian

Copyright (๑) 2012 Sheng-Fu Yu et al. This is an open access article distributed under the Creative Commons Attribution License, which permits unrestricted use, distribution, and reproduction in any medium, provided the original work is properly cited.

The optical and electrical characteristics of InGaN-based blue light-emitting diodes (LEDs) grown on patterned sapphire substrates (PSSs) with different pattern heights and on planar sapphire by atmospheric-pressure metal-organic chemical vapor deposition were investigated. Compared with planar sapphire, it was found that the LED electroluminescence intensity is significantly enhanced on PSSs with pattern heights of $0.5(21 \%), 1.1(57 \%), 1.5(81 \%)$, and $1.9(91 \%) \mu \mathrm{m}$ at an injected current of $20 \mathrm{~mA}$. The increased light intensity exhibits the same trend in a TracePro simulation. In addition, it was also found that the level of leakage current depends on the density of V-shape defects, which were measured by scanning electron microscopy.

\section{Introduction}

InGaN-based light-emitting diodes (LEDs) are useful for a wide range of visiblelight applications. They are commonly used in traffic signals, liquid crystal display backlights, microprojectors, car headlights, and fullcolor displays, among other applications. White LEDs have significant potential for becoming a popular lighting choice because of their advantages in terms of energy consumption, device lifetime, durability, and safety, along with their ecofriendliness. In general, white LEDs are fabricated using a blue LED with yellow phosphors. Because of their high external quantum efficiency (EQE), blue LEDs have attracted considerable attention. According to an analysis of the lighting market by the U.S. Department of Energy, the blue-based white LED will be increasingly popular in the coming decades. Although white LEDs have become very efficient [1-3], further improvements are still needed to enable them to replace traditional candescent and fluorescent lamps for commercial applications.
EQE is affected by both internal quantum efficiency (IQE) and the light extraction rate. A high IQE value over $90 \%$ has been anticipated in recent years, but the light extraction rate is still extremely low because the refractive index of GaN $(n=2.3)$ is higher than air $(n=1)$. The critical angle is roughly $24.6^{\circ}$, which indicates that less light is extracted from the surface [4]. For this reason, several alternative approaches have been introduced to improve light extraction efficiency, including approaches that make use of $p$-GaN roughness [5], indium tin oxide (ITO) mesh [6], a laser liftoff process [7], and a patterned sapphire substrate (PSS) [8-11]. In particular, use of a PSS not only enhances the light extraction rate but also decreases threading dislocation defects because the growth mechanism is similar to epitaxial lateral overgrowth (ELOG) [12]. Moreover, a PSS with an uninterrupted single growth process has higher production yields. However, very rough substrates can cause epitaxial growth problems, such as generation of V-pit defects and staking fault formation. Related defects can degrade aspects of the PSS-LED's performance, such as its electrostatic 


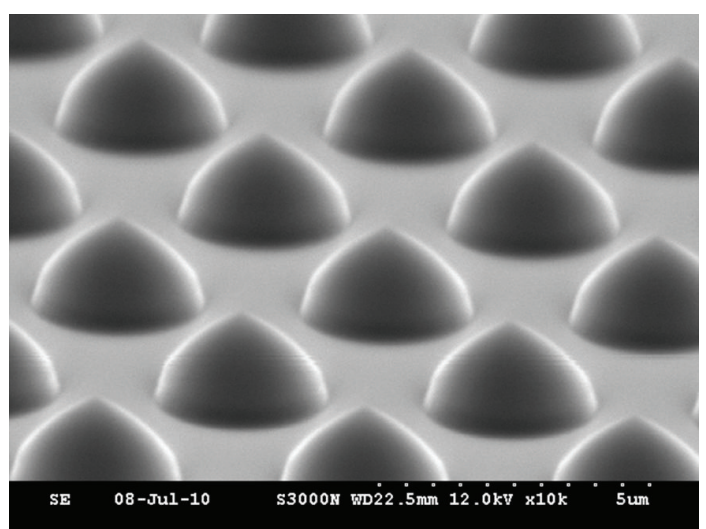

FIGURE 1: SEM image of patterned substrate with pattern diameter of roughly $3 \mu \mathrm{m}$ and pattern distance of roughly $2 \mu \mathrm{m}$.

discharge (ESD) capabilities, device lifetime, leakage current, and quantum efficiency of radiative recombination. Defects that are related to the use of different pattern heights in the sapphire substrate, such as degraded electrical performance, have rarely been examined.

In this study, we grew the standard LED structure on patterned sapphire substrates with varying pattern heights, and on a planar sapphire substrate. The light extraction efficiency was evaluated for the different pattern heights and compared to results obtained using TracePro optical simulation software. In addition, we also evaluated the leakage current and used SEM measurements to characterize its relationship to V-pit defects.

\section{Experiment}

The patterned height sapphire substrate was etched using inductively coupled plasma (ICP) reactive ion etching. After dry etching, the pattern diameter and pattern distance were roughly $3 \mu \mathrm{m}$ and $2 \mu \mathrm{m}$, respectively. The etching times were varied to generate pattern heights of 0 (planar sapphire), 0.5 , $1.1,1.5$, and $1.9 \mu \mathrm{m}$, which were then verified by confocal microscopy. A scanning electron microscopy (SEM) image of one of the cone-shaped patterns is shown in Figure 1.

After fabrication, blue InGaN/GaN LEDs were grown on the substrates using atmospheric pressure metal organic chemical vapor deposition (AP-MOCVD) with an SR2000 system. Trimethylgallium (TMGa), trimethylaluminum (TMAl), trimethylindium (TMIn), and ammonia $\left(\mathrm{NH}_{3}\right)$ were used as precursors. Silane $\left(\mathrm{SiH}_{4}\right)$ and bis(cyclopentadienyl)magnesium $\left(\mathrm{Cp}_{2} \mathrm{Mg}\right)$ were used as the $n$-dopant and $p$-dopant sources. The LED structure consisted of a $25 \mathrm{~nm}$ thick GaN nucleation layer, a $2.5 \mu \mathrm{m}$ thick undoped GaN layer, a $2 \mu$ m thick highly doped $n$-type $\mathrm{GaN}$ layer, five pairs of $\mathrm{InGaN}(2.5 \mathrm{~nm}) / \mathrm{GaN}(12.5 \mathrm{~nm})$ MQWs, a 25-nm-thick p-type AlGaN electron blocking layer, and a $100 \mathrm{~nm}$ thick $\mathrm{Mg}$-doped $\mathrm{GaN}$ layer. The u-GaN growth temperature was increased to $1180^{\circ} \mathrm{C}$ to achieve better coalescence on the patterned sapphire substrate (relative to using the typical temperature of roughly

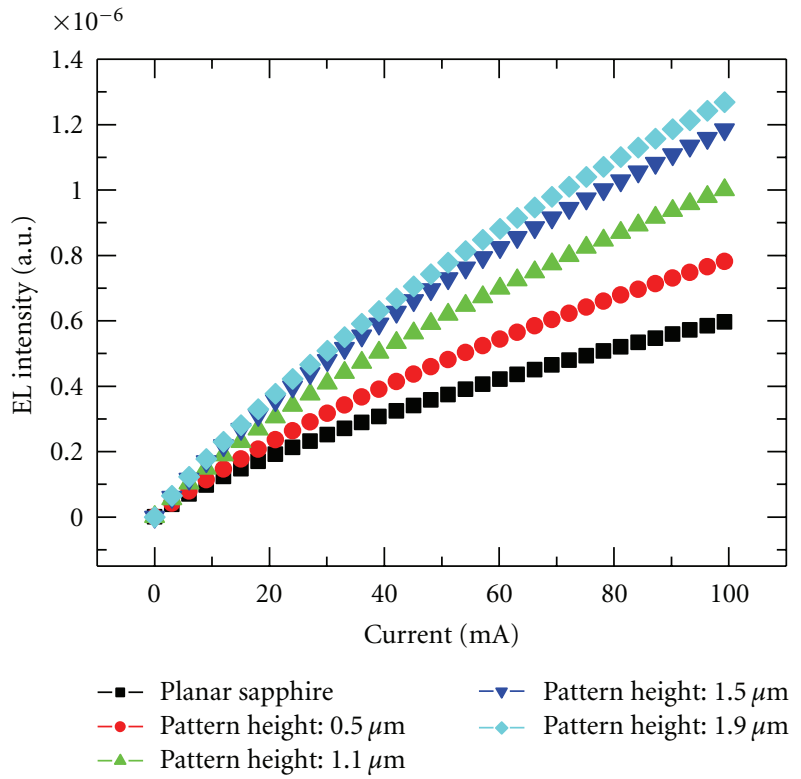

FiguRE 2: EL intensity for different pattern heights as a function of injected current.

$1130^{\circ} \mathrm{C}$ ). After the LEDs were grown on the substrates, the samples were then treated in a quartz furnace under an $\mathrm{N}_{2}$ atmosphere to activate the $\mathrm{Mg}$-doped $\mathrm{GaN}$. The annealing temperature and elapsed time were $700^{\circ} \mathrm{C}$ and 30 minutes, respectively. LEDs with $300 \times 300 \mu \mathrm{m}^{2}$ sizes were formed by conventional photolithography followed by chlorine-based inductively coupled plasma etching. Both $p$ - and $n$-contacts were located on the epitaxial surface. ITO was employed as a $p$-type transparent contact layer electrode in order to reduce the optical absorption of the $p$-type electrode.

The patterned substrate and LED epitaxial surface morphology were evaluated using field emission scanning electron microscopy (FE-SEM). Using a semiconductor laser $(405 \mathrm{~nm})$ as the exciting source, the photoluminescence (PL) was used to evaluate the devices' optical properties. The devices' electrical characteristics were evaluated by measuring their electroluminescence (EL), light output current, and current-voltage curve. TracePro simulation software was used to simulate the light extraction efficiency of the different pattern heights.

\section{Results and Discussion}

Figure 2 illustrates the light output intensity versus the injected current for different pattern heights on the sapphire substrate and for the planar sapphire LED. The L-I measurement was based on a $300 \times 300 \mu \mathrm{m}^{2}$ chip located on a wafer. The light output intensity showed remarkable improvement for pattern heights of $0.5,1.1,1.5$, and $2.0 \mu \mathrm{m}$; the intensities for these heights were about $21,57,81$, and 91\% higher (resp.) than for the LED on a normal planar sapphire substrate at an operating current of $20 \mathrm{~mA}$. These results suggest that higher patterned sapphire substrates can improve light extraction efficiency. A previous study [13] 


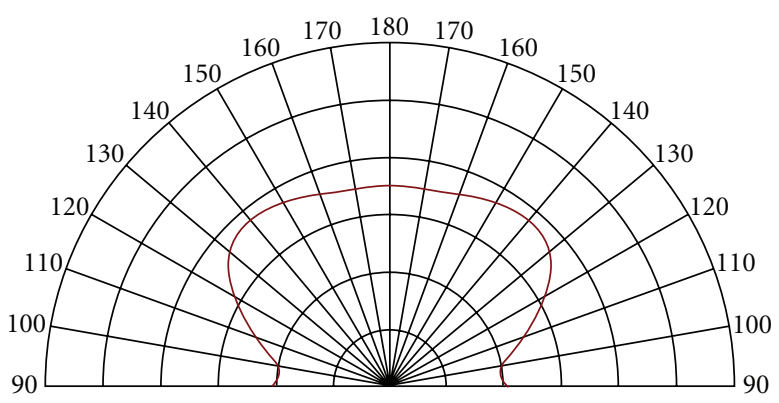

(a)

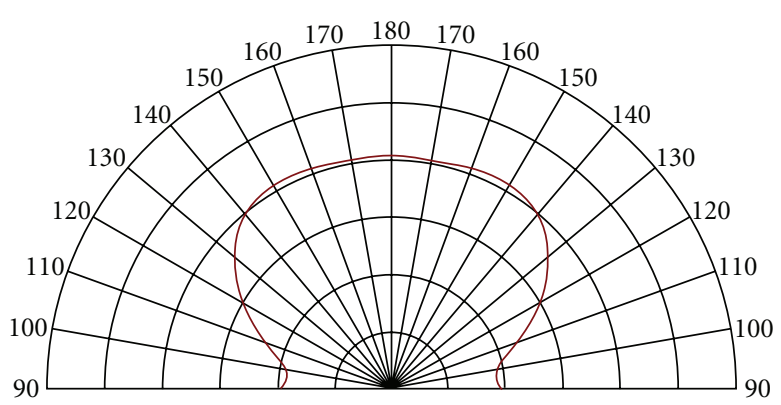

(b)

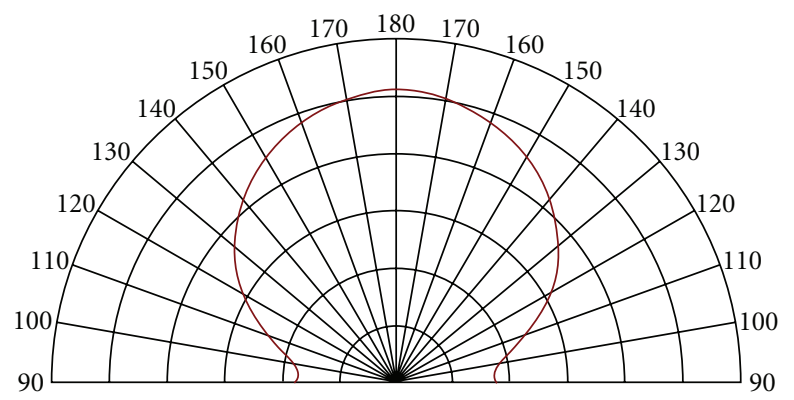

(c)

FIgURE 3: Far-field emission patterns for LEDs made with (a) planar sapphire, (b) a pattern height of $1.1 \mu \mathrm{m}$, and (c) a pattern height of $1.9 \mu \mathrm{m}$.

used Monte Carlo ray tracing software to simulate the light extraction efficiency (LEE) for different angles of a pyramidtype PSS LED. As the pattern angle increased, the light extraction efficiency became larger and reached its maximum value, meaning a larger angle corresponds to a higher pattern height. Therefore, the simulated results agreed with our experimental data.

TracePro software was used to simulate the devices and determine why a higher pattern height yielded a higher LEE. Figure 3 displays the far-field emission patterns of the LED on (a) planar sapphire, (b) a $1.1 \mu \mathrm{m}$ pattern height, and (c) a $1.9 \mu \mathrm{m}$ pattern height. The simulation parameters were based on a previous report [13] that was used as a reference. From the far-field pattern, it is clear that the output beam pattern shows more vertical pattern of emissions and the total extraction increases as the pattern height increases. Higher patterns may provide additional light scattering effects and decrease the total reflection, which is laterally guided by the planar sapphire-GaN-air.

We then used the TracePro software to simulate the light extraction rate of the LED on both the planar sapphire and on the sapphire substrates with varying pattern heights. The critical lighting source was placed inside the multiquantum well (MQW) of our simulated LED standard structure with a chip size of $300 \times 300 \mu \mathrm{m}^{2}$. The pattern diameter and space were $3 \mu \mathrm{m}$ and $2 \mu \mathrm{m}$, respectively. The only aspect of the structure that was varied was the bottom substrates. These were cone-shaped patterned sapphire substrates with pattern heights of 0 (planar sapphire), $0.5,1.1,1.5$, and $1.9 \mu \mathrm{m}$. The parameters shown above are identical to the real substrates of our samples. Next, a parallel absorbed plank was placed

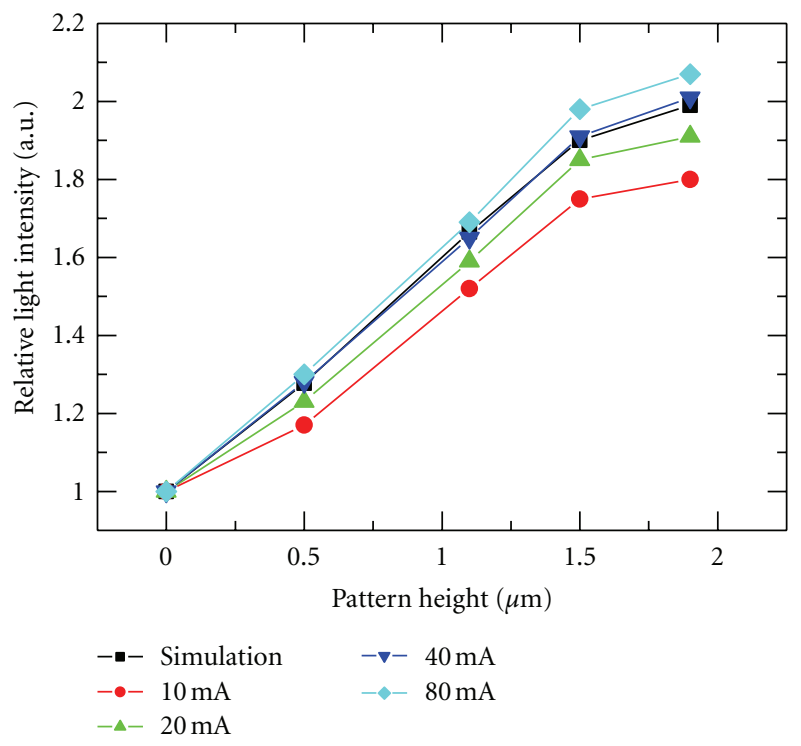

FIGURE 4: Relative light intensity with various patterned height substrate under $10 \mathrm{~mA}, 20 \mathrm{~mA}, 40 \mathrm{~mA}, 80 \mathrm{~mA}$, and TracePro simulation result.

on top of the LED structure for use as a detector. This detector conforms to the wafer-on-chip assessment of the EL measurement. Simulation results for the relative light intensity normalized to the intensity of the LED on the planar sapphire are shown in Figure 4. The relative light intensity exhibited a nearly linear increase as a function of the pattern 


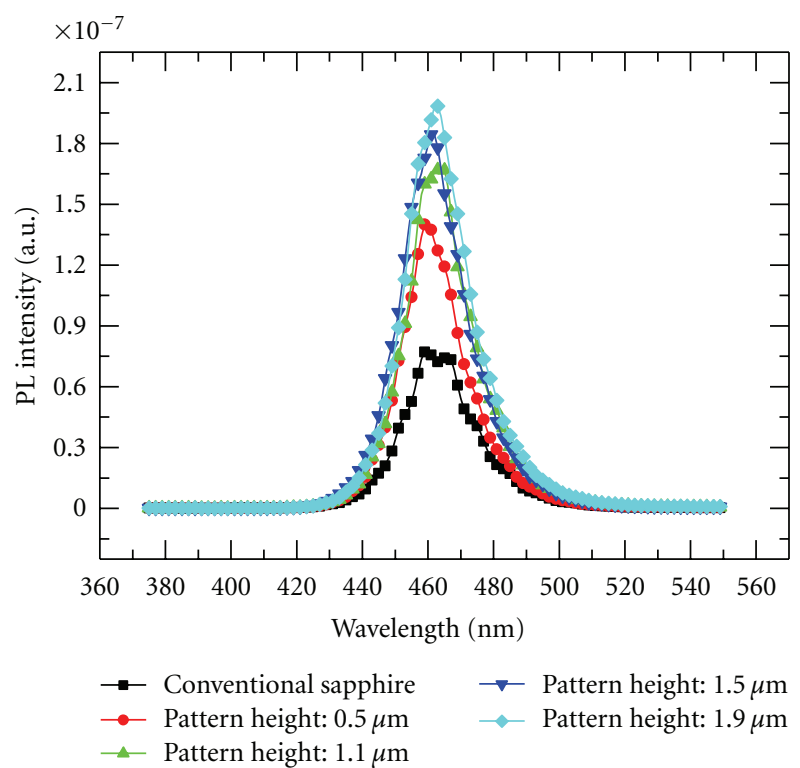

Figure 5: Photoluminescence (PL) measurement at room temperature for LED on planar sapphire and substrate pattern heights of $0.5,1.1,1.5,1.9 \mu \mathrm{m}$.

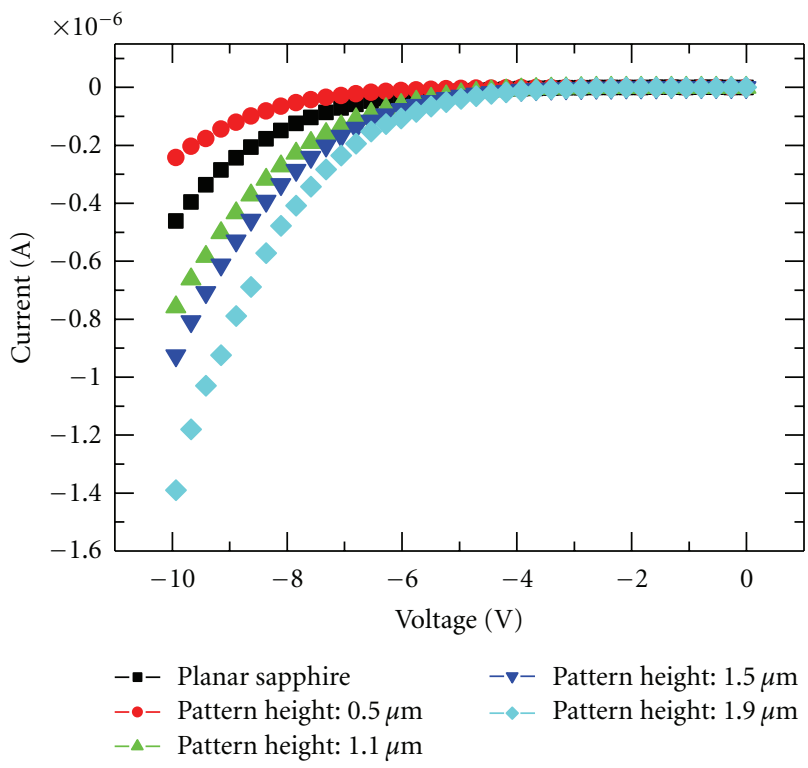

FIGURE 6: Leakage current under reverse voltage for PSS and planar sapphire LEDs.

height. Comparing these results to our EL measurement results with a current of $10,20,40$, and $80 \mathrm{~mA}$, the relative light intensity of different pattern heights LEDs were also normalized to the intensity of the LED on planar sapphire. They all displayed the same trend as in our simulation results even under different current operation.

Figure 5 shows the room temperature PL measurement for the LED grown on a planar sapphire substrate and on the sapphire substrates with different pattern heights. The excited PL intensity demonstrated significant improvement as the PSS was introduced and gradually increased as the pattern height increased. This phenomenon is also a result of the enhanced scattering effect of the patterned sapphire substrate. In addition, the full width at half maximum (FWHM) values for the samples on planar sapphire and on the PSS with pattern heights of $0.5,1.1,1.5$, and $1.9 \mu \mathrm{m}$ were $22.23,20.24,21.05,21.18$, and $21.19 \mathrm{~nm}$, respectively. All of the FWHM values for the LEDs on the PSS are smaller than that of the LED on the sapphire substrate, suggesting that the crystal quality was considerably improved by using the PSS. On the other hand, the amount of leakage current in the LED affects the LED production yields. The leakage current is known to be associated with electrical properties such as electrostatic discharge (ESD) [14] and with defect levels. Figure 6 shows the typical leakage current under reverse bios as a function of the LED on planar sapphire and on the sapphire substrates with varying pattern heights. The leakage current of the PSS LED with a pattern height of $0.5 \mu \mathrm{m}$ was roughly $-0.25 \mu \mathrm{A}$, which is lower than those of the normal sapphire LED value of $-0.48 \mu \mathrm{A}$ at a reverse voltage of $-10 \mathrm{~V}$. However, the leakage currents for the pattern heights of $1.0,1.5$, and $1.9 \mu \mathrm{m}$ were $-0.78 \mu \mathrm{A},-0.95 \mu \mathrm{A}$, and $-1.4 \mu \mathrm{A}$, respectively, which were larger than that of the normal sapphire LED. To illustrate this effect, we evaluated the V-pit defect measurements for each sample. Figure 7 shows the plane view of FE-SEM images of the LED on sapphire and on sapphire substrates with different pattern heights. The density of the $\mathrm{V}$-pits is calculated to be roughly $1.7 \times 10^{6}, 1.0 \times 10^{6}, 2.0 \times 10^{6}, 2.7 \times 10^{6}$, and $4.7 \times 10^{6} \mathrm{~cm}^{-2}$ for the LED on planar sapphire and with pattern heights of $0.5,1.1,1.5$, and $1.9 \mu \mathrm{m}$, respectively. Comparing these results to those for the planar sapphire LED, the $\mathrm{V}$-pit density decreases for the LED with a $0.5 \mu \mathrm{m}$ height PSS and then increases as the pattern height increases. We believe that the $\mathrm{V}$-pit density is associated with the leakage current of LED devices because the $\mathrm{V}$-shaped defects are related to the threading dislocations (from our previous report [15]) and may create a route for leakage current. According to the literature [16], use of a patterned sapphire substrate would effectively decrease the number of threading dislocations and $\mathrm{V}$-pit defects. This would reduce the leakage current because the growth mode is similar to epitaxial lateral overgrowth (ELOG) on a PSS. However, in our case, only the LED with the $0.5 \mu \mathrm{m}$ pattern height showed this characteristic, though the higher PPS did produce another stacking fault coming from the rough substrate. We believe that this problem can be diminished while increasing $\mathrm{u}-\mathrm{GaN}$ thickness or improve lateral growth via modified epirecipe. In general, the $\mathrm{u}-\mathrm{GaN}$ thickness in a standard LED structure on a sapphire substrate is roughly $2 \mu \mathrm{m}$. In this study, the $\mathrm{u}-\mathrm{GaN}$ thickness was increased to almost $2.5 \mu \mathrm{m}$ to cover additional defects in the PSS. However, the higher the pattern, the more difficult to lateral coalesce. The more severe stacking fault may occur on the top of the pattern. In particular, the top of pattern corresponds to strong stree. These stress centers may create another newborn threading dislocation that penetrates the following epilayer, ultimately causing V-pit defects on the LED surface. 


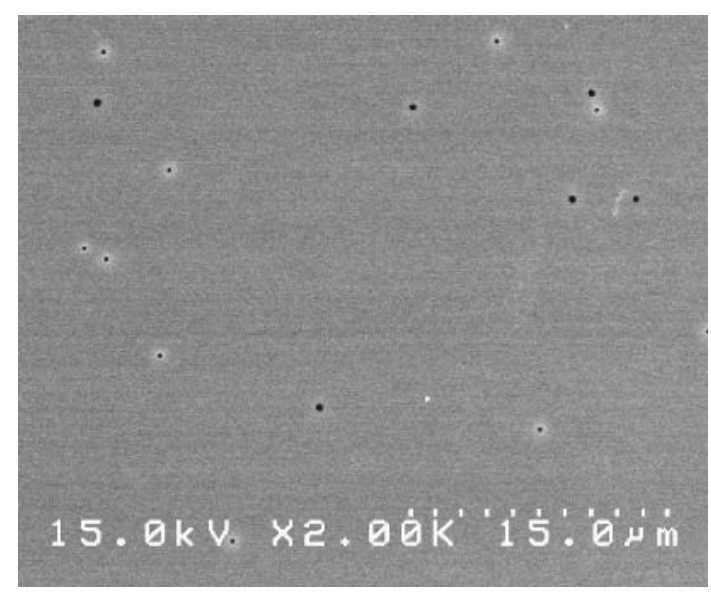

(a)

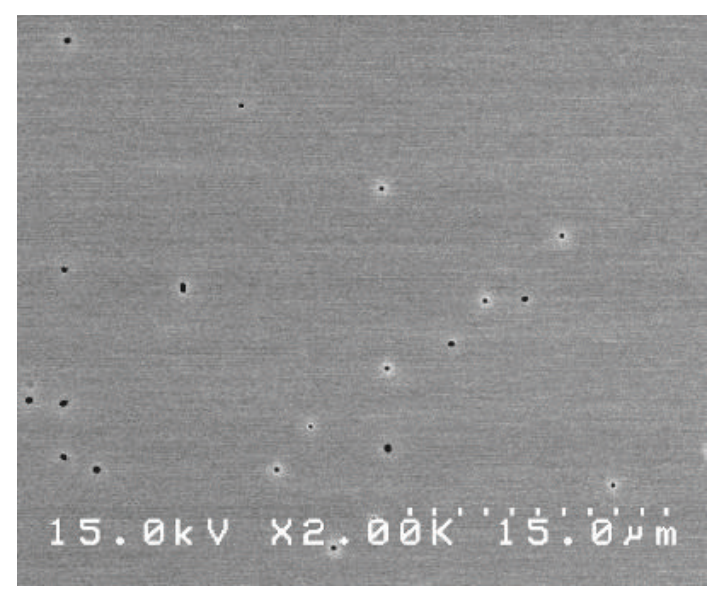

(c)

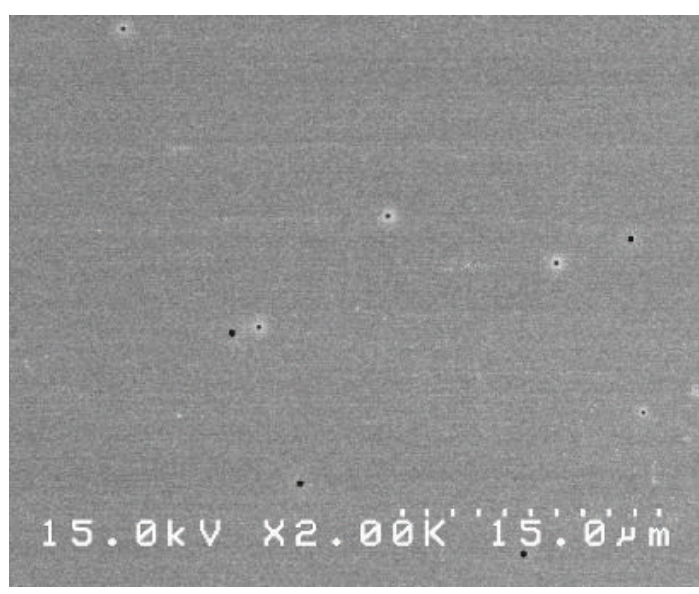

(b)

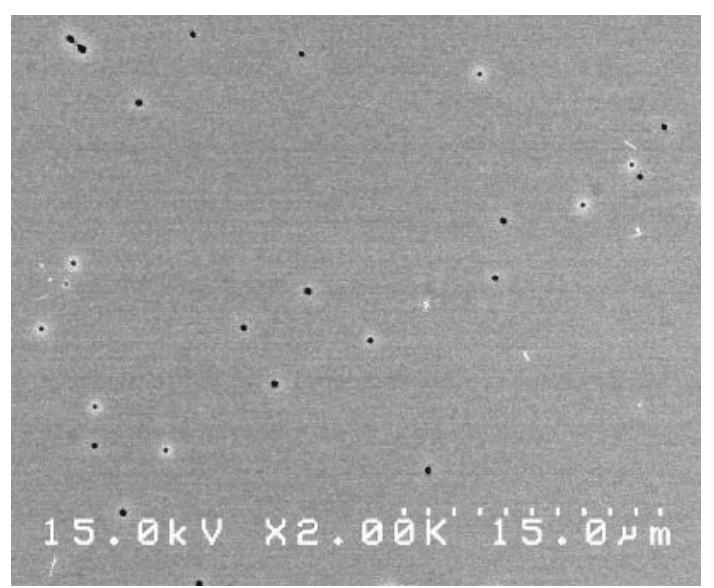

(d)

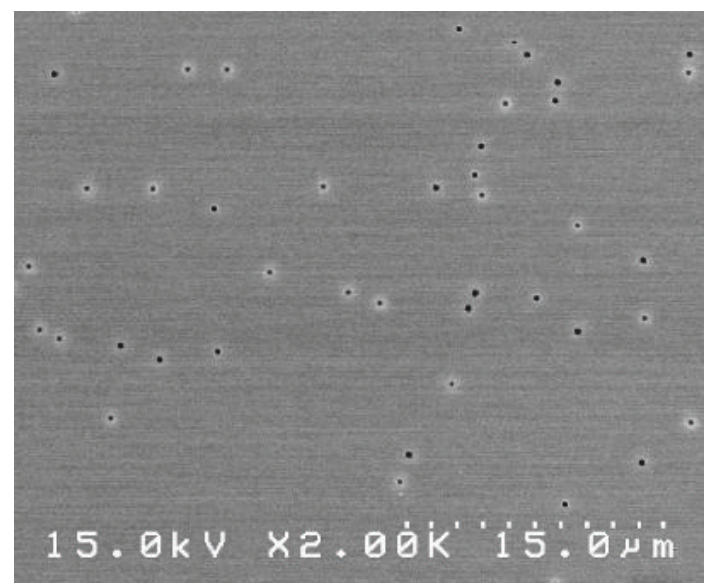

(e)

FigURE 7: FE-SEM images of LED surface morphology on (a) planar sapphire and substrates with pattern heights of (b) $0.5 \mu \mathrm{m}$, (c) $1.1 \mu \mathrm{m}$, (d) $1.5 \mu \mathrm{m}$, and (e) $1.9 \mu \mathrm{m}$.

\section{Conclusions}

This paper evaluates the effect of different pattern heights on the light extraction efficiency of InGaN-based blue LEDs.
At $20 \mathrm{~mA}$, the highest EL intensity increased by $91 \%$ for an LED with a $1.9 \mu \mathrm{m}$ pattern height on a sapphire substrate as compared to an LED on planar sapphire. Furthermore, according to TracePro simulations, the expected light output 
intensity depends on the pattern height; this result agreed with our experimental results. Finally, we found that the thickness of the $\mathrm{u}-\mathrm{GaN}$ epilayer or modified $\mathrm{u}-\mathrm{GaN}$ epilayer used in the PSS structure plays an important role in creating leakage current and should be considered as part of the LED design process.

\section{Acknowledgments}

The authors would like to thank the National Science Council and Bureau of Energy, Ministry of Economic Affairs of Taiwan, Taiwan for the financial support under Contract no. 100-2221-E-006-168 and 101-D0204-6 and the LED Lighting Research Center of NCKU for the assistance of device characterization. This work was also supported in part by the Center for Frontier Materials and Micro/Nano Science and Technology, the National Cheng Kung University, Taiwan. This work was also supported in part by the Advanced Optoelectronic Technology Center, the National Cheng Kung University, under projects from the Ministry of Education.

\section{References}

[1] Y. Narukawa, M. Sano, M. Ichikawa et al., "Improvement of luminous efficiency in white light emitting diodes by reducing a forward-bias voltage," Japanese Journal of Applied Physics, vol. 46, part 2, no. 36-40, pp. L963-L965, 2007.

[2] A. Laubsch, M. Sabathil, J. Baur, M. Peter, and B. Hahn, "Highpower and high-efficiency InGaN-based light emitters," IEEE Transactions on Electron Devices, vol. 57, no. 1, pp. 79-87, 2010.

[3] J. Baur, F. Baumann, M. Peter et al., "Status of high efficiency and high power ThinGaN-LED development," Physica Status Solidi C, vol. 6, no. 2, pp. S905-S908, 2009.

[4] C. Huh, K. S. Lee, E. J. Kang, and S. J. Park, "Improved light-output and electrical performance of InGaN-based lightemitting diode by microroughening of the p-GaN surface," Journal of Applied Physics, vol. 93, no. 11, pp. 9383-9385, 2003.

[5] C. M. Tsai, J. K. Sheu, W. C. Lai et al., "Enhanced output power in GaN-based LEDs with naturally textured surface grown by MOCVD," IEEE Electron Device Letters, vol. 26, no. 7, pp. 464466, 2005.

[6] C. H. Kuo, C. M. Chen, C. W. Kuo et al., "Improvement of near-ultraviolet nitride-based light emitting diodes with mesh indium tin oxide contact layers," Applied Physics Letters, vol. 89, no. 20, Article ID 201104, 2006.

[7] K. T. Lee, Y. C. Lee, J. Y. Chang, and J. Gong, "Improvement on optical properties of GaN light-emitting diode with meshtextured sapphire back delineated by laser scriber," IEEE Photonics Technology Letters, vol. 21, no. 7, pp. 477-479, 2009.

[8] J. H. Lee, D. Y. Lee, B. W. Oh, and J. H. Lee, "Comparison of InGaN-based LEDs grown on conventional sapphire and cone-shape-patterned sapphire substrate," IEEE Transactions on Electron Devices, vol. 57, no. 1, pp. 157-163, 2010.

[9] S. M. Jeong, S. Kissinger, D. W. Kim et al., "Characteristic enhancement of the blue LED chip by the growth and fabrication on patterned sapphire $\left(\begin{array}{llll}0 & 0 & 0 & 1\end{array}\right)$ substrate," Journal of Crystal Growth, vol. 312, no. 2, pp. 258-262, 2010.

[10] A. R. Lee, H. Jeon, G.-S. Lee et al., "Characterization of the InGaN/GaN multi-quantum-wells light-emitting diode grown on patterned sapphire substrate with wide electroluminescence spectrum," Japanese Journal of Applied Physics, vol. 50, part 2, Article ID 01AD06, 2011.

[11] C. H. Chan, C. H. Hou, S. Z. Tseng et al., "Improved output power of GaN-based light-emitting diodes grown on a nanopatterned sapphire substrate," Applied Physics Letters, vol. 95, no. 1, Article ID 011110, 2009.

[12] H. Marchand, J. P. Ibbetson, P. T. Fini et al., "Mechanisms of lateral epitaxial overgrowth of gallium nitride by metalorganic chemical vapor deposition," Journal of Crystal Growth, vol. 195, no. 1-4, pp. 328-332, 1998.

[13] T. X. Lee, K. F. Gao, W. T. Chien, and C. C. Sun, "Light extraction analysis of GaN-based light-emitting diodes with surface texture and/or patterned substrate," Optics Express, vol. 15, no. 11, pp. 6670-6676, 2007.

[14] Y. K. Su, S. J. Chang, S. C. Wei, S. M. Chen, and W. L. Li, "ESD engineering of nitride-based LEDs," IEEE Transactions on Device and Materials Reliability, vol. 5, no. 2, pp. 277-281, 2005.

[15] S. F. Yu, S. J. Chang, R. M. Lin et al., "Growth of quaternary AlInGaN with various TMI molar rates," Journal of Crystal Growth, vol. 312, no. 12-13, pp. 1920-1924, 2010.

[16] R. M. Lin, Y. C. Lu, S. F. Yu et al., "Enhanced extraction and efficiency of blue light-emitting diodes prepared using two-step-etched patterned sapphire substrates," Journal of the Electrochemical Society, vol. 156, no. 11, pp. H874-H876, 2009. 

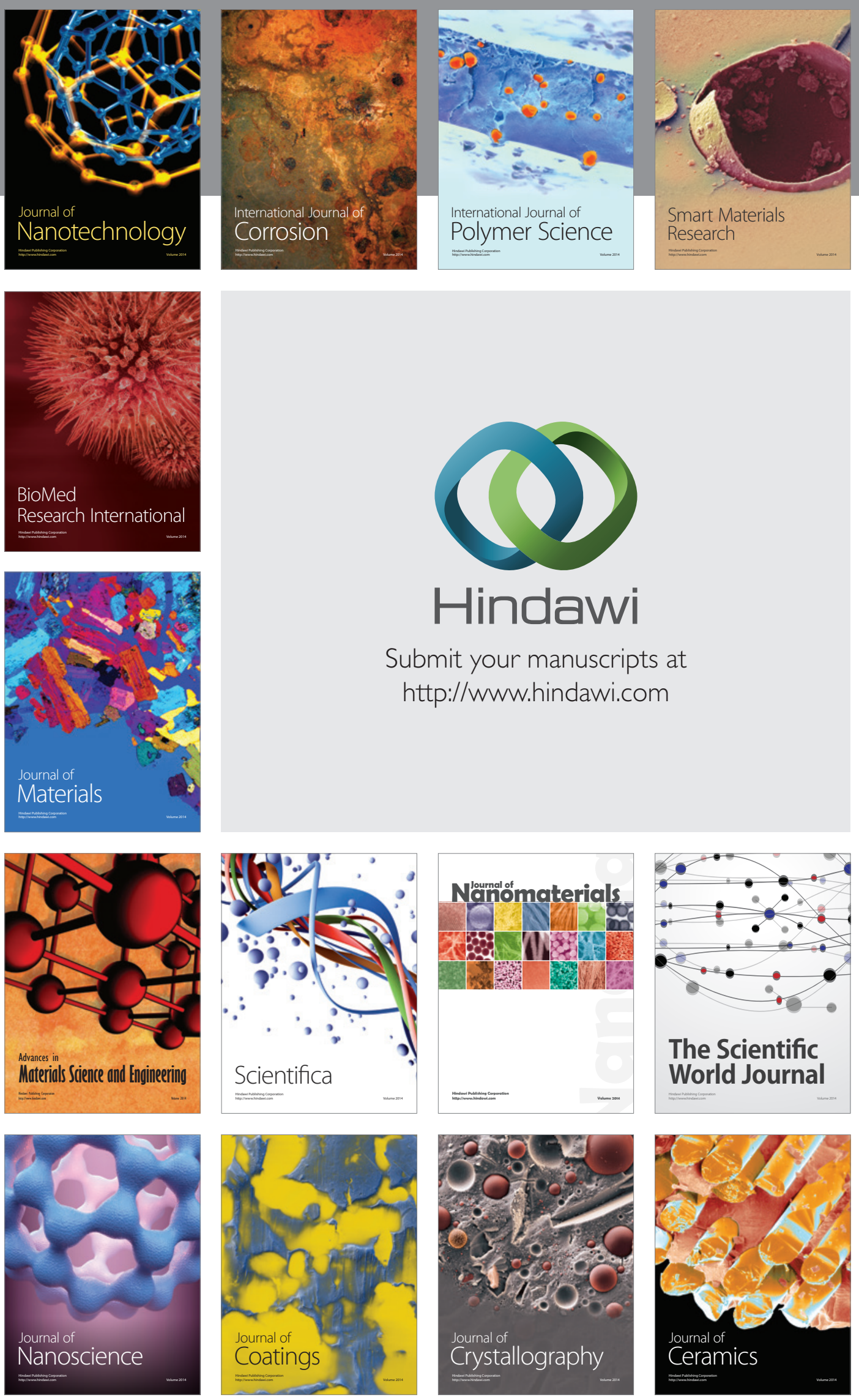

The Scientific World Journal

Submit your manuscripts at

http://www.hindawi.com

\section{World Journal}

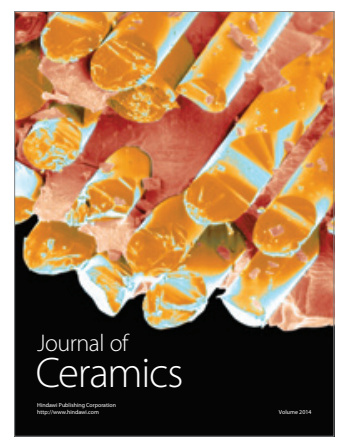

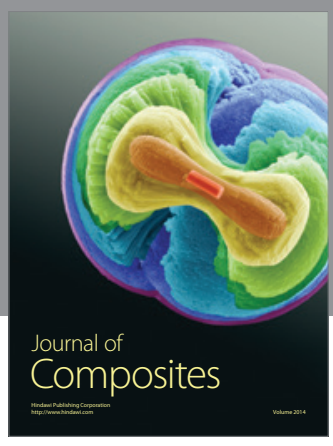
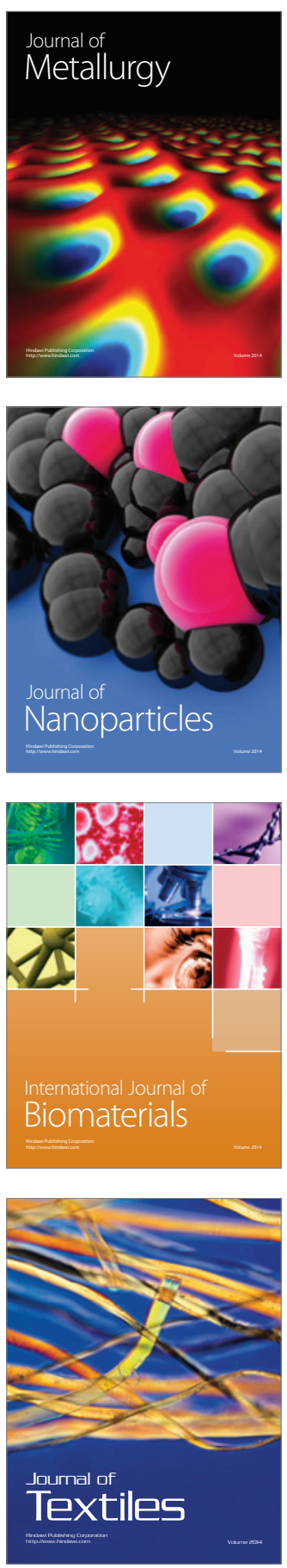